Voces

\section{Patrimonio cultural tradicional y homogeneización}

Ivan Pivotti

Licenciado en Ciencias Políticas

Ante el reto de escribir un artículo sobre la situación del patrimonio cultural frente a los fenómenos estructurantes del mundo contemporáneo, me encontré en la dificultad de enfocar las relaciones entre pasado y presente, identidad y homologación. La re-lectura de algunos fragmentos de la obra del intelectual friulano Pier Paolo Pasolini me ayudó a profundizar y concretar un poco el asunto

Como por muchos otros aspectos socio-políticos del mundo que vivimos, la visión "con perspectiva" de Pasolini nos puede ayudar a comprender el significado del patrimonio cultural en el mundo contemporáneo. Sobre todo, si nos referimos al patrimonio intangible constituido por el conjunto de formas de una cultura tradicional o popular, como pueden ser la lengua, las habilidades y conocimientos especiales relacionados con aspectos materiales de esta cultura determinada, u otras manifestaciones identitarias que tienen que ver con las relaciones interpersonales colectivas.

Es sorprendente (o no lo es tanto) encontrar en la obra literaria y cinematográfica de Pasolini una resistencia a la "brutal homogeneización totalitaria del mundo", defendiendo la importancia de lo que él denominaba las "fuerzas del pasado", de la tradición. Sorprende, porque la actual mitigación de las diferencias o de la diversidad es un fenómeno muy relacionado con los ideales incorruptibles del progreso y del crecimiento propios de la globalización de los mercados, pero que, evidentemente, estaba presente también con antelación al auge de la palabra "globalización": cuando Pasolini todavía vivía y pensaba. Él buscaba en el recuerdo del Friúl rural de su infancia y en la diversidad cultural y dialectal amenazadas un arma en contra de la "modernización" y también del "progresismo" cuando éstos significan conformismo y uniformidad. Los conceptos de modernidad, progreso o crecimiento han representado, y siguen representando, objetivos compartidos por las ideologías políticas del siglo XX, sean o no capitalistas. Consecuentemente, la única resistencia a la homogeneización de las diferencias que tales paradigmas comportan está representada por la recuperación y la salvaguardia de las identidades colectivas tradicionales, con su patrimonio cultural y su sistema de valores. Tanto es así, que incluso un pensador marxista (por muy atípico e iluminado que fuera) como Pasolini, en una Italia donde la lucha de clase predominaba sobre las luchas por las libertades de los diferentes grupos étnicos, fue capaz de entender que la defensa del pasado, en lo que a relaciones sociales y productivas locales se refiere, es la única lucha que podemos afrontar sin que se nos escape de las manos.

El poder conjunto del mercado y de los medios de comunicación, lo que Pasolini llamaba "nuevo fascismo", es lo que hoy en día llamamos globalización neoliberal, sobre todo si consideramos la tendencia a la difusión y penetración de los mecanismos de mercado en todos los aspectos de nuestras vida. Tanto es así, que no sólo se han mercantilizado (desde lo público o desde lo privado, la diferencia substancial no es mucha, cuando está dirigido al lucro) las obras de arte materiales, sino también muchos fenómenos sociales intangibles y, por su naturaleza, efímeros, se están viendo afectados por este proceso. Un extremo de este proceso es representado por la práctica, llevada a cabo por muchas empresas transnacionales en el sur del planeta, de patentar conocimientos y habilidades relacionadas con la explotación tradicional de algunos recursos colectivos de pueblos indigenas para, de tal manera, poseer la propiedad intelectual de una práctica especifica que les permite utilizar en exclusiva los recursos en cuestión. Se trata, como podemos ver, de un caso límite en todo el complejo fenómeno de la ofensiva al patrimonio cultural de los pueblos: un robo tutelado por el derecho internacional es la manifestación más cruel, y quizás de momento la menos frecuente, de la hegemonía de un sistema mucho más sutil, que sólo puede reproducirse a sí mismo en cuanto pueda asegurar su penetración en todas las construcciones sociales alternativas y, por lo tanto, diferentes. Pero, sin ir tan lejos y quedándonos en nuestras vivencias cotidianas, la pérdida de costumbres tradicionales en el ámbito del ocio (sitios de reunión como locales de barrio y plazas públicas suplantados por centros comerciales) y del negocio (eliminación de mercados de abastos urbanos y de prácticas rurales como puede ser la mecanización de la matanza del cerdo) nos ayuda quizás a comprender los efectos de lo que pretendo evidenciar.

Es curioso observar cómo, en relación con este patrimonio cultural inmaterial, existen dos dinámicas globalizadoras contemporáneas y, sólo aparentemente, contradictorias. En efecto, por un lado hay una fuerza general tendente a nivelar las diferencias entre colectivos para crear una masa indiferenciada de consumidores; puesto que la economía de mercado tiene como objetivo generar, favorecer y estimular el consumo de bienes y servicios 0 , lo que es lo mismo, crear necesidades, la manera más eficaz de minimizar los costes de producción es la de uniformar el consumo en todas partes, de crear consumidores modelo. Por otro lado, hay un empuje a conservar algunos rasgos identitarios útiles para ser comercializados en aras del turismo (sector de momento muy remunerativo en regiones climáticamente 0 artísticamente favorecidas como Andalucía) o exportados globalmente, como a veces pasa con la gastronomía, la música, y otras artes (por ejemplo, las cadenas de restaurantes étnicos o algunos circuitos de lo que se denomina "world music").

Al mismo tiempo, esta doble faceta contribuye a dar una ilusión de que estos cambios aportan mucho más de lo que sustraen y que, de todas maneras, son algo ventajoso e irreversible. Afortunadamente sabemos, porque somos seres sociales, que todo fenómeno humano, empezando por el relacionado con las construcciones sociales, es ampliamente reversible y mejorable: esto significa, no sólo que podemos lícitamente oponernos a la fuerza homogeneizadora, sino también que no podemos fosilizarnos en la defensa del pasado en cuanto tal, porque la sociedad es mutable, viva y vital. 